\title{
Efficient removal of $17 \beta$-estradiol using hybrid clay materials: Batch and column studies
}

\author{
Thanhmingliana $^{1}$, C. Lalhriatpuia ${ }^{1}$, Diwakar Tiwari ${ }^{2}$, Seung-Mok Lee ${ }^{{ }^{+}}$ \\ ${ }^{1}$ Department of Chemistry, Pachhunga University College, Aizawl, Mizoram 796001, India \\ ${ }^{2}$ Department of Chemistry, School of Physical Sciences, Mizoram University, Aizawl, Mizoram 796004, India \\ ${ }^{3}$ Department of Health and Environment, Catholic Kwandong University, Gangwon-do, Gangneung 25601, Republic of Korea
}

\begin{abstract}
Hybrid materials were obtained modifying the bentonite (BC) and local clay (LC) using hexadecyltrimethylammonium bromide (HDTMA) or the clay were pillared with aluminum followed by modification with HDTMA. The materials were characterized by the SEM, FT-IR and XRD analytical tools. The batch reactor data implied that the uptake of $17 \beta$-estradiol (E2) by the hybrid materials showed very high uptake at the neutral $\mathrm{pH}$ region. However, at higher and lower $\mathrm{pH}$ conditions, slightly less uptake of E2 was occurred. The uptake of E2 was insignificantly affected changing the sorptive concentration from 1.0 to $10.0 \mathrm{mg} / \mathrm{L}$ and the background electrolyte ( $\mathrm{NaCl}$ ) concentrations from 0.0001 to 0.1 $\mathrm{mol} / \mathrm{L}$. Moreover, the sorption of E2 by these hybrid materials was fairly efficient since within 30 mins of contact time, an apparent equilibrium between solid and solution was achieved, and the data was best fitted to the PSO (pseudo-second order) and FL-PSO (Fractal-like-pseudo second order) kinetic models compared to the PFO (pseudo-first order) model. The fixed-bed column results showed that relatively high breakthrough volume was obtained for the attenuation of E2 using these hybrid materials, and the loading capacity of E2 was estimated to be 75.984, 63.757, 58.965 and $49.746 \mathrm{mg} / \mathrm{g}$ for the solids $\mathrm{BCH}, \mathrm{BCAH}, \mathrm{LCH}$ and $\mathrm{LCAH}$, respectively.
\end{abstract}

Keywords: Clay, Estrogen, Hybrid materials, Hydrophobic, Kinetics, Sorption

\section{Introduction}

Micro-pollutants in the aquatic environment pose serious environmental concerns because of their persistency and toxicity towards living organisms. There are several natural and synthetic chemicals that show endocrine disruption and cause interference in the reproduction and development of aquatic organisms [1]. 17 $\beta$ -Estradiol (E2) is one of the most potent forms of natural estrogen and is identified as a potential water pollutant among several endocrine disrupting chemicals (EDCs). This is because it triggers greatly the negative responses in aquatic organisms even at very low concentrations [2]. It is often found in surface and subsurface aquatic environment [3]. Human and animal urine and feces as in the form of free estrogens or as glucuronide and/or sulfate conjugates are the major sources of these pollutants into the aquatic environment. Although these steroid conjugates do not show affinity to estrogen receptors, however, these are converted into deconjugated forms by chemical or enzymatic means in sewage treatment plants, and hence are considered as potential and emerging sources of active estrogens which lead to adverse reproductive effects on ecosystems [4].

The effect of these hormones on human health at environmentally relevant concentrations is, of course, unclear. However, the effect of E2 on non-target organisms, including endocrine disruption is affecting sexual development and reproduction [5-6]. The formation of female specific vitellogenin was reported in male rainbow trout when exposed to E2 concentration as low as $1 \mathrm{ng} / \mathrm{L}$ [7]. Similarly, the exposure of male Japanese medaka to $10 \mathrm{ng} / \mathrm{L}$ E2 was induced the production of female-specific proteins, resulted the formation of intersex (ova in the testes) and altered sex species [8]. Therefore, an efficient and cost effective treatment processes need to be developed in order to fine tune the existing wastewater treatment plants. Sorptive removal using variety of newer materials is one of possible options for decontaminating the aquatic environment contaminated with steroidal estrogens. In fact, a number of sorbent materials have been applied for eliminating E2 including surface soils [6], granular activated carbon (GAC), chitin, chitosan, ion exchange resin, carbonaceous adsorbent prepared from industrial waste [9], natural sediments [10], bone char [11], powdered activated carbons [12], single-walled carbon nanotubes [13], mul-
This is an Open Access article distributed under the terms of the Creative Commons Attribution Non-Commercial License (http://creativecommons. org/ licenses/by-nc/3.0/) which permits unrestricted non-commercial use, distribution, and reproduction in any medium, provided the original work is properly cited.
Received January 8, 2016 Accepted March 14, 2016

${ }^{\dagger}$ Corresponding author

Email: leesm@cku.ac.kr

Tel: +82-33-649-7535 Fax: +82-33-642-7635

Copyright (C) 2016 Korean Society of Environmental Engineers 
ti-walled carbon nanotubes [14] polyamide thin-film composite nanofiltration (NF) membranes [15], and molecularly imprinted polymer [16]. However, these sorbents suffer the problem of either low sorption capacities or seemingly high-cost of materials. Thus, there need to search a high-performance and low-cost adsorbent for an efficient removal of micro-pollutants from aqueous environments.

The applications of porous pristine clays in the remediation of aquatic environment was often employed however, the removal capacities of pristine clay was reportedly low towards several hydrophobic impurities. Therefore, the modified clay materials were intended to employ in the selective and specific removal of micro-pollutants from aqueous solutions. The introduction of cationic surfactant within inter lamellar space through the ion exchange process caused significantly the chemical properties of clay minerals. This apparently enhances the hydrophobic/organophilic character of clay and the modified clays are likely to be effective/efficient towards the organic pollutants attenuation [17]. Similarly, the hybrid materials obtained by pillaring with poly(hydroxo-metal) cations and simultaneous intercalation of suitable organic cations showed an enhanced applicability in wastewater treatment since this showed fairly high affinity towards the organic impurities, and also possessed with achievable settling capacity which enabled it easy for phase separation [18].

Therefore, the present study aims to obtain and employ the hybrid materials, precursor to the natural bentonite or locally collected clay in an attempt to attenuate E2 efficiently and effectively from aquatic environments. Further, the batch reactor operations are conducted in a wide range of chemical parametric studies which provides a plausible mechanism involved at the solid/solution interface, along with the fixed-bed column reactor operations to optimize the loading capacity of E2 under the dynamic conditions.

\section{Materials and Methods}

\subsection{Materials}

Local clay was collected from the field of Phullen, Mizoram (India). It possessed with several impurities hence; it was thoroughly separated using the ISRIC (International Soil Reference and Information Centre) standard method as detailed elsewhere [19]. However, the bentonite clay (BC) was procured from a commercial supplier and was used after simple washing with distilled water and dried at $90^{\circ} \mathrm{C}$ in a drying oven. The two clay samples were crushed in a mortar and sieved to obtain 100 BSS (British Standard Sieve) mesh size particles. The cation exchange capacity (CEC) of pristine clay was determined by the US EPA (United States Environmental Protection Agency) method 9080 [20]. The CEC of BC and LC were found to be 69.35 and $46.38 \mathrm{meq} / 100 \mathrm{~g}$ of clay, respectively. Aluminium (III) chloride was obtained from Merck, India. Hexadecyltrimethylammonium bromide (HDTMA) and 17b-Estradiol (E2) were procured from Sigma-Aldrich, USA. Sodium chloride, Extrapure was obtained from HiMedia, India. Water purified with a Millipore water purification system (Milli$\mathrm{Q}+$ ) was used throughout the whole experiment.<smiles>[R17]C([SiH3])([SiH3])[SiH3]</smiles>

\subsection{Methods}

\subsubsection{Preparation of organoclay and inorgano-organoclay}

$\mathrm{BC}$ or LC was modified by the usual wet cation exchange process as described earlier [21]. In brief, $20 \mathrm{~g}$ of each clay powder was added separately into $1 \mathrm{~L}$ of HDTMA solution to saturate $100 \%$ of the respective clay CEC. The slurry was refluxed for $48 \mathrm{~h}$ at $60^{\circ} \mathrm{C}$ under constant stirring. It was filtered and the solid was washed several times with purified water. Excess or free surfactant was removed with Soxhlet extraction. The organo-modified bentonite/or local clay was dried at $90^{\circ} \mathrm{C}$ in a drying oven and then stored in an airtight polyethylene bottle. The HDTMA-modified $\mathrm{BC}$ and LC were then labeled as $\mathrm{BCH}$ and $\mathrm{LCH}$ respectively.

The bentonite and/or local clay was pillared with aluminium and then modified with organic cations HDTMA as to obtain the HDTMA-Al-bentonite (BCAH) or HDTMA-Al-local clay (LCAH) materials. In brief, aluminium(III) solution was prepared by mixing $100 \mathrm{~mL}$ of $0.4 \mathrm{~mol} / \mathrm{L} \mathrm{NaOH}$ and $100 \mathrm{~mL}$ of $0.2 \mathrm{~mol} / \mathrm{L}$ aluminium(III) chloride solutions under vigorous and constant stirring. The solution mixture was kept for 7 days for ageing at room temperature. Further, in this aluminium solution a known amount of HDTMA (to saturate $100 \%$ of the clay CEC) was added under stirred conditions. BC or LC clay powders (4 g) each in $300 \mathrm{~mL}$ of water was then taken in round bottom flask. To this solution mixture, HDTMA-aluminium solution was added and stirred for Ca. $5 \mathrm{~h}$ at room temperature. The slurry was then kept at room temperature for another 2 days. The modified clay was separated carefully and the solid was washed with plenty of distilled water as to obtain materials free from the halides or any unbound/free HDTMA. These solids were then dried at $50^{\circ} \mathrm{C}$ in a drying oven and grounded gently in a mortar. The AL-HDTMA-modified BC and LC were then labeled as BCAH or LCAH, respectively.

\subsubsection{Characterization of materials}

The surface morphology of the hybrid materials and the pristine clay was obtained using the FE-SEM (Field Emission Scanning Electron Microscope: Model S-4700, Hitachi, Japan) images. X-ray diffraction (XRD) data were collected using an X-ray diffraction machine (PANalytical, Netherland; Model X'Pert PRO MPD), employing $\mathrm{Cu}-\mathrm{K}_{\alpha}$ radiations having the wavelength of $1.5418 \AA$. FT-IR (Fourier Transform-Infra Red) data was obtained with a FT-IR machine (Bruker, Tensor 27, USA using KBR disk method). The point of zero charge (pHPZC) of these materials was determined by the batch $\mathrm{pH}$ drift method as detailed elsewhere [22].

\subsubsection{Batch reactor experiments}

A stock solution $(10.0 \mathrm{mg} / \mathrm{L})$ of E2 was prepared by dissolving an appropriate amount of E2 in purified water at elevated $\mathrm{pH}$ 
with dilute $\mathrm{NaOH}$. Further, the required E2 concentration was obtained by dilution of the stock solution and the $\mathrm{pH}$ was adjusted with the dropwise addition of $0.1 \mathrm{~mol} / \mathrm{L} \mathrm{HCl}$. The $\mathrm{pH}$ dependence sorption experiment was carried out by taking a series of $5.0 \mathrm{mg} / \mathrm{L}$ of E2 solution ( $50 \mathrm{~mL}$ ) into polyethylene bottles and the $\mathrm{pH}$ was adjusted by drop wise addition of $0.1 \mathrm{~mol} / \mathrm{L} \mathrm{HCl}$ or $\mathrm{NaOH}$ solutions. $0.1 \mathrm{~g}$ of the solid sample was introduced into these sorptive solutions. The bottles were kept in an automatic incubator shaker (Incubator Shaker, TM Weiber, ACMAS Technologies Pvt. Ltd., India) for 24 hours at $25 \pm 1^{\circ} \mathrm{C}$. The bottles were then taken out from the shaker and the solution mixture was filtered with $0.45 \mu \mathrm{m}$ syringe filter. The $\mathrm{pH}$ was again checked and reported as equilibrium $\mathrm{pH}$. Absorbance of the filtrates was measured using UV-Visible Spectrophotometer (Model: UV1, Thermo Electron Corporation, USA). The absorbance was recorded at $280 \mathrm{~nm}$. Calibration curve was obtained using standard E2 solutions having varied concentrations. Results were presented as percent E2 removal as a function of equilibrium $\mathrm{pH}$. The blank E2 (5.0 mg/L) solutions were shaken without the hybrid materials in the polyethylene bottles for $24 \mathrm{~h}$. The samples were filtered with a $0.45 \mathrm{~mm}$ syringe filter and their absorbance was determined at the same wavelength of $280 \mathrm{~nm}$. No decrease in absorbance was observed, which indicated that negligible sorption of E2 was occurred to the polyethylene bottles.

The concentration dependence data was collected by varying the E2 concentrations from 1.0 to $10.0 \mathrm{mg} / \mathrm{L}$ at constant $\mathrm{pH} \sim 7.0$ and at constant temperature $\left(25 \pm 1^{\circ} \mathrm{C}\right)$. Results were presented as percent E2 removal as a function of initial E2 concentration (mg/L). Time dependence sorption of E2 by these hybrid materials was obtained at different time intervals of contact. Initial E2 concentration $5.0 \mathrm{mg} / \mathrm{L}$ with a solid dose of $2.0 \mathrm{~g} / \mathrm{L}$ was taken as constant and the sorption experiments were conducted at constant $\mathrm{pH} \sim 7.0$ and temperature $25 \pm 1^{\circ} \mathrm{C}$. Results were then reported as percent E2 removal as a function of time (min.). Effect of background electrolyte concentration on the sorption of E2 was studied varying the $\mathrm{NaCl}$ concentration from 0.0001 to $0.1 \mathrm{~mol} / \mathrm{L}$ with E2 concentration of $5.0 \mathrm{mg} / \mathrm{L}$. The solution $\mathrm{pH}(\sim 7.0)$ and temperature $(25$ $\pm 1^{\circ} \mathrm{C}$ ) was kept constant throughout the experiments. Results were again presented as percent E2 removal as a function of background electrolyte $(\mathrm{NaCl})$ concentrations.

\subsubsection{Fixed-bed column experiments}

Fixed-bed column experiments were conducted using a glass column (1 cm inner diameter). $0.25 \mathrm{~g}$ of hybrid materials was kept in the middle of the column. Below and above the hybrid material, $1.0 \mathrm{~g}$ of sand (14-16 BSS) was placed and the rest of the column was packed with glass beads. E2 $(5.0 \mathrm{mg} / \mathrm{L})$ solution at $\mathrm{pH} \sim 7.0$ was pumped up from the bottom of the column using a peristaltic pump (KrosFlo Research I Peristaltic Pump, Spectrum Laboratories Inc., California, USA), at a constant flow rate of $1.0 \mathrm{~mL} / \mathrm{min}$. Effluent solution was collected using a fraction collector (Spectra/Chrom CF-2 Fraction Collector, Spectrum Laboratories Inc., California, USA). The collected effluents were filtered with $0.45 \mu \mathrm{m}$ syringe filter and absorbance of the filtrate was measured with UV-Vis Spectrophotometer.

Column breakthrough data obtained were utilized to optimize the loading capacity of E2 by the materials under the dynamic conditions employing Thomas equation [23]:

$$
\frac{C_{e}}{C_{o}}=\frac{1}{1+e^{\left(K_{T}\left(q_{o} m-C_{o} V\right)\right) / Q}}
$$

where $\mathrm{C}_{\mathrm{e}}$ and $\mathrm{C}_{\mathrm{o}}$ are the concentrations (mg/L) of effluent and influent solutions of E2, respectively; $\mathrm{K}_{\mathrm{T}}$ refer to the Thomas rate constant (L/min/mg); $\mathrm{q}_{o}$ is the maximum amount (mg/g) of E2 loaded under the specified column conditions; ' $m$ ' is the mass (g) of hybrid materials taken in the column; $\mathrm{V}$ is the throughput volume (L); and Q is the flow rate (L/min) of pumped E2 solution. The column data were fitted to a non-linear Thomas equation using the least square fitting method to estimate the two unknown parameters, $K_{T}$ and $q_{\mathrm{o}}$.

\section{Results and Discussion}

\subsection{Characterization of Materials}

FT-IR data indicated that the hybrid materials, viz., BCH, BCAH, LCH or LCAH were possessed with prominent IR stretching bands at around the wave numbers $2930 \mathrm{~cm}^{-1}$ and $2850 \mathrm{~cm}^{-1}$ which were due to the $-\mathrm{CH}_{2}$ asymmetric and symmetric stretching vibrations, respectively (Fig. S1). This confirmed the introduction of HDTMA molecule within the clay network with these hybrid materials. Bentonite and local clay XRD data was matched with the standard ICDD (International Centre for Diffraction Data) reference pattern. It was noted that both the clay samples contained with quartz, smectite, illite and kaolinite minerals with varied percent composition as characteristic peaks were assigned in the XRD diffraction pattern. Further, quantitatively, the bentonite was having $43.71 \%, 23.17 \%, 1.73 \%$ and $31.39 \%$ of quartz, smectite, kaolinite and illite, respectively. Similarly, local clay was contained with $79.35 \%, 6.20 \%, 0.45 \%$ and $14.01 \%$, respectively of quartz, smectite, kaolinite and illite. The XRD patterns of the modified clay samples were almost identical to the pristine clay, with a slight change in d-values and intensities of the peaks (Fig. S2). The FE-SEM images clearly show that the organo-modified clay (i.e., BCH or LCH) solids possessed more heterogeneous surface structures compared to the pristine clays (Fig. S3). BCAH and LCAH solids also possessed similar heterogeneous surface structure, although they contained with newly aggregated particles onto the surface which were possibly the immobilized aluminium hydroxide or $\mathrm{Al}_{2} \mathrm{O}_{3}$ molecules. Detailed characterizations of these materials were described previously [21].

The BET specific surface area, pore volume and pore size of these solids, viz., BC, BCH, BCAH, LC, LCH and LCAH were obtained by the nitrogen adsorption and desorption method and results were returned in Table 1 . It was observed that BC was having very high value of the BET specific surface area, with low pore volume and pore size. The high specific surface area of BC was due to the high percentage of smectite, kaolinite and illite mineral phases compared to the quartz/silica content. However, the HDTMA- or Al-HDTMA-modified bentonite materials were showed a remarkable decrease in specific surface area and an increased in pore size (diameter) and pore volume of the materials. It was due to the fact that the HDTMA or aluminium were occupied the interspace of clay and caused to decrease the 
Table 1. BET Pore Size, Specific Pore Volume and Specific Surface Area Values of the Clay and Hybrid Materials

\begin{tabular}{cccc}
\hline Materials & Pore Size $(\mathbf{n m})$ & Specific pore volume $\left(\mathbf{c m}^{3} / \mathbf{g}\right)$ & BET Specific $\mathbf{~ s u r f a c e ~} \mathbf{a r e a}^{\left(\mathbf{c m}^{2} / \mathbf{g}\right)}$ \\
BC & 4.98 & 0.010 & 80.86 \\
BCH & 36.60 & 0.050 & 4.68 \\
BCAH & 27.45 & 0.075 & 9.55 \\
LC & 30.67 & 0.025 & 2.94 \\
LCH & 13.12 & 0.045 & 11.87 \\
LCAH & 8.04 & 0.010 & 4.55 \\
\hline
\end{tabular}

specific surface area of clay, whereas the propping up of the interlayer was caused to enhance the pore size and pore volume of the solids. On the other hand, the unmodified local clay (LC) showed very significantly low specific surface area, possibly, due to the compact surface structure of LC which contained dominantly with the silica/quartz. However, the presence of HDTMA or Al-HDTMA caused to increase slightly the specific surface area of solids with a decrease in pore diameter of the modified solids.

\subsection{Batch Reactor Operations}

\subsubsection{Effect of $\mathrm{pH}$}

The $\mathrm{pH}$ dependence removal of $\mathrm{E} 2$ ( $\mathrm{pH} 4.02$ to 10.13) by these solids was presented graphically in Fig. 1. It was observed that a very high uptake of E2 was achieved within the studied $\mathrm{pH}$ region. It was further recorded that a slight decrease in sorption of E2 was observed at very low and high $\mathrm{pH}$ values. The uptake of E2 by these solids could be ascribed with the help of speciation of E2 as well the surface properties of the solids. E2 is having the acid dissociation constant $\left(\mathrm{pK}_{\mathrm{a}}\right)$ of 10.23 [14], which indicated that E2 exists as a neutral molecule almost up to $\mathrm{pH} \sim 10.2$ and carries a net negative charge above this $\mathrm{pH}$ value. On the other hand, the $\mathrm{pH}_{\mathrm{PZC}}$ value of these solids was found to be 9.8, 8.2, 6.1, 5.8, 5.1 and 5.1 for the samples BC, BCH, BCAH, LC, LCH and LCAH respectively. This implied that except BC and $\mathrm{BCH}$ solid, other materials possessed a net negative charge at and around neutral $\mathrm{pH}$. Therefore, the possibility of electrostatic attraction of E2 by the solid surface was, perhaps, ruled out. Hence, the possible interaction of E2 with the solid surface was due to the hydrophobic or organophilic nature of the hybrid materials. The mechanism of E2 uptake by these hybrid materials is therefore, assumed primarily with the fact that the introduction of organic cation (HDTMA) within the clay network caused to enhance the hydrophobicity or organophilic nature of the surface. This enabled E2 to partition at the introduced hydrophobic core. On the other hand; LCAH solid showed slightly less uptake of E2, possibly, due to the screening of the introduced HDTMA molecule in presence of aluminium oxide/hydroxide particles onto the solid surface. Hence, this caused to reduce the hydrophobic core within the clay network. Further, the removal of E2 was decreased to some extent with increasing the solution $\mathrm{pH}$ to10.0. This is due to the partial acidic dissociation of E2. This caused, to some extent, for electrostatic repulsion and hence was reduced in partitioning of E2 within the hydrophobic core of the hybrid materials. It was reported previously that the organoclays prepared with longer

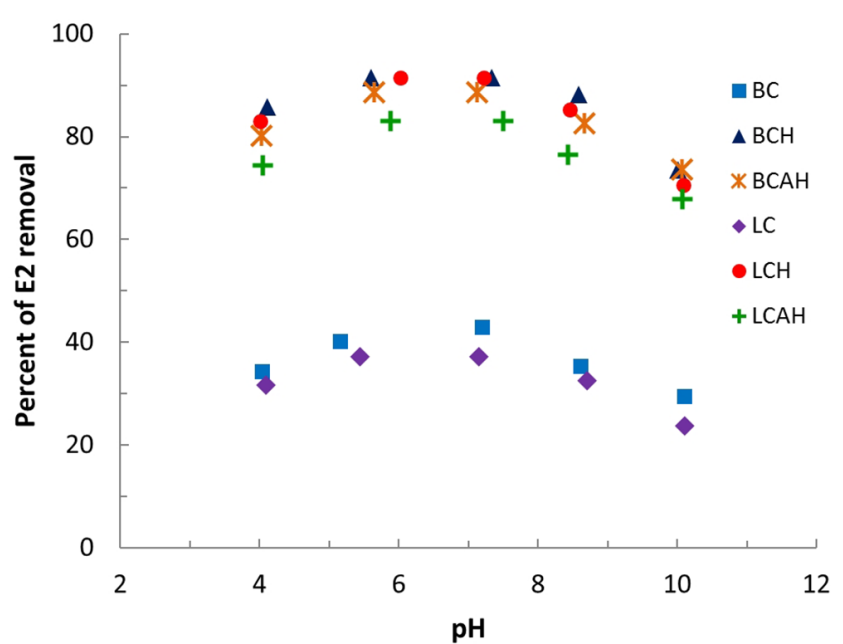

Fig. 1. Effect of $\mathrm{pH}$ on the removal of E2 using different materials.

chain surfactant molecule were less influenced by the solution $\mathrm{pH}$ [24]. Moreover, the hybrid materials precursor to natural sericite and modified with HDTMA and alkyldimethylbenzylammonium chloride were used in the remediation of wastewaters contaminated with $\mathrm{BPA}$, and the increased in $\mathrm{pH}$ from $\mathrm{ca}$. 2.0 to 10.0 did not significantly affect the percentage uptake of BPA by these hybrid materials [22]. It was also noted that the virgin bentonite and local clay showed very insignificant or significantly less uptake of E2 (ca. $42.86 \%$ and $37.14 \%$ at $\mathrm{pH} 7.21$ and 7.16 for BC and LC, respectively), which was further decreased at low and high $\mathrm{pH}$ conditions. The sorption of E2 by all these hybrid materials, compared to the unmodified clays, show significantly enhanced percent uptake and enhanced the applicability of hybrid materials at least in the remediation of water contaminated with E2 pollutant.

\subsubsection{Effect of E2 concentration}

The effect of initial sorptive concentration is one of the effective factors in estimating the sorption efficiency/capacity. The sorption of E2 was obtained as a function of initial sorptive concentrations and was presented in Fig. 2(a). The figure revealed that increasing the initial concentration of E2 from Ca. 1.0 to $10.0 \mathrm{mg} / \mathrm{L}$, a very high percent uptake was not significantly affected with this increase in sorptive concentration ( $c f$. Fig. 2(a)) However, on the other hand, the amount of E2 removal was increased significantly, increasing the initial E2 concentration (Fig. 2(b)). These results again indicated the strong affinity of E2 towards the hybrid materials and an effective attenuation of E2 was obtained. 

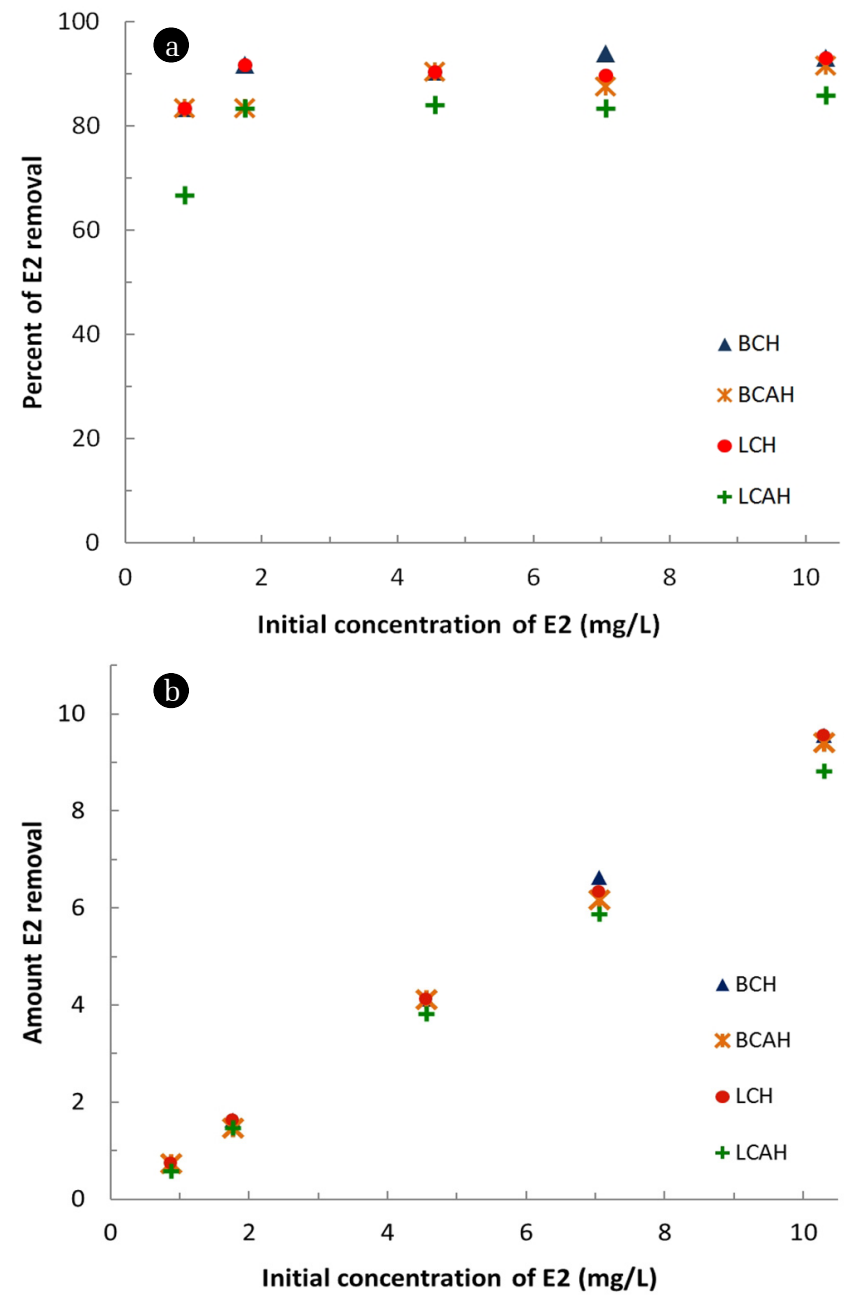

Fig. 2. Effect of initial E2 concentration on the removal of E2 using various hybrid materials.

\subsubsection{Effect of background electrolyte concentration}

Effect of background electrolytes in the sorptive removal of E2 by the hybrid materials could help to explain the mechanism involved at solid/solution interface. The specific sorption is usually not much influenced by the change in background electrolyte concentrations; whereas the non-specific sorption is greatly influenced by the change in background electrolyte concentrations [25]. The percent removal of E2 as a function of background electrolyte $(\mathrm{NaCl})$ concentrations is shown graphically in Fig. 3. The results indicated that increasing the background electrolyte concentrations from 0.0001 to $0.1 \mathrm{~mol} / \mathrm{L} \mathrm{NaCl}$ (i.e., 1000 times increase) was not significantly affected the percent uptake of E2 by the hybrid materials, i.e., BCH, BCAH, LCH and LCAH. This indicated again the strong affinity of solids towards E2. This implied that the partitioned E2 was bound with relatively stronger van der Waals forces which retained firmly the E2 molecule onto or within the interspace of hybrid materials. Previously, it was reported that the increase in $\mathrm{NaCl}$ concentration from 0 to $320 \mathrm{~mm}$ did

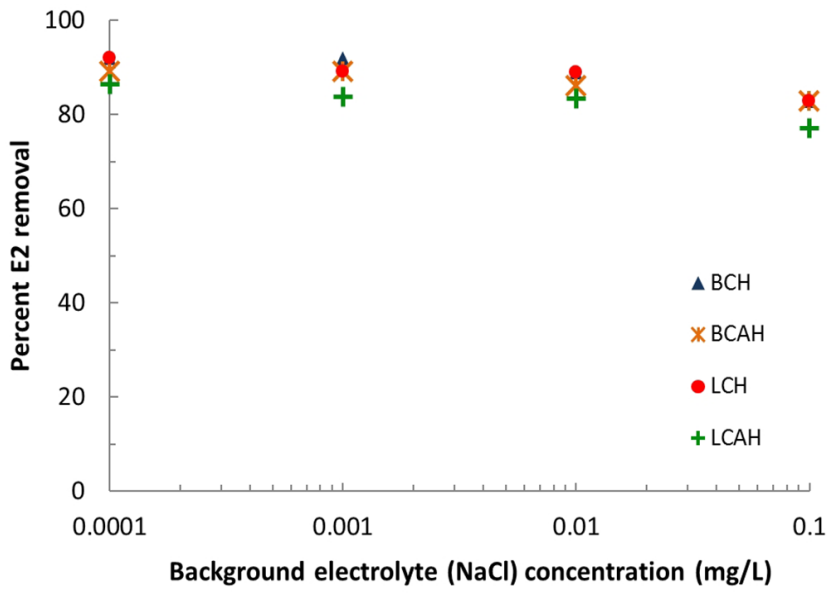

Fig. 3. Effect of background electrolyte $(\mathrm{NaCl})$ concentration on the removal of E2.

not significantly change the adsorption of $17 \alpha$-ethinylestradiol (EE2) from landfill leachate onto single-walled carbon nanotubes (SWCNTs) [26]. Also the uptake of As(V) was almost unaffected by the 1000 times increase in background electrolyte concentration, using manganese coated activated carbon samples. It was further stated that $\mathrm{As}(\mathrm{V})$ were specifically sorbed onto the solid surface and predominantly formed 'inner-sphere complexes' onto the solid surface [27].

\subsubsection{Time dependence removal}

The percent of E2 removed as a function of time was plotted in Fig. 4. It was evident from the fig. that the materials were efficient in the removal of E2 from aqueous solutions since within initial 10-15 min of contact, a maximum E2 were aggregated onto the solid surface and was resulted in maximum percent uptake of E2. This was then gradually slowed down and an apparent equilibrium was achieved within ca. 30 min of contact. This again reaffirmed the affinity of these solids towards E2. Also it was again noted that the uptake of E2 onto the LCAH solid was slightly lesser than the other hybrid materials.

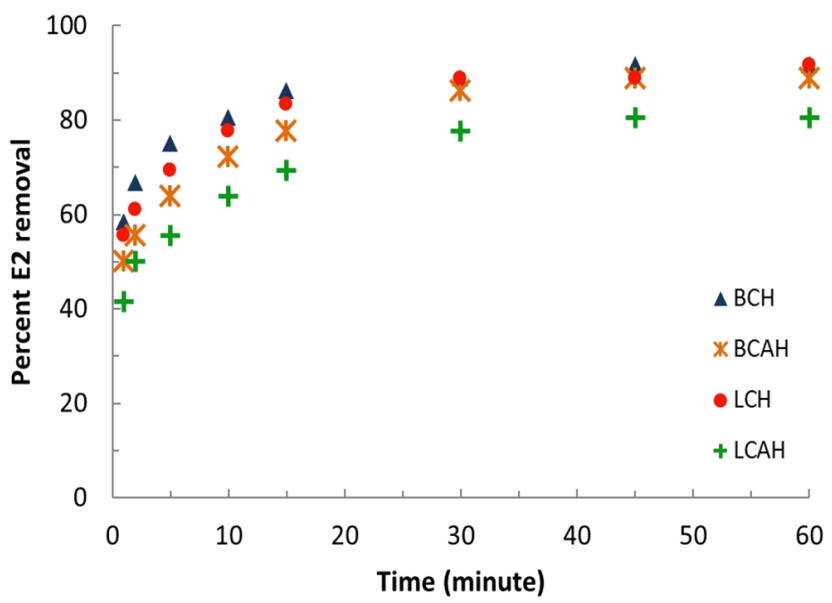

Fig. 4. Effect of contact time on the removal of E2 by various hybrid materials. 
The time dependence sorption data was then utilized to perform the kinetic modelling. The non-linear form of three different kinetic models, viz., pseudo-first order (PFO) [28], pseudo-second order (PSO) [29] and fractal-like pseudo-second order (FL-PSO) [30] models (Eq. (2)- (4)) were utilized:

$$
\begin{gathered}
q_{t}=q_{e}\left(1-\exp \left(-k_{1} t\right)\right) \\
q_{t}=\frac{k_{2} q_{e} 2_{t}}{1+k_{2} q_{e} t} \\
q_{t}=\frac{k q_{e} 2_{t} \alpha}{1+k q_{e} t^{\alpha}}
\end{gathered}
$$

where $\mathrm{q}_{\mathrm{t}}$ and $\mathrm{q}_{\mathrm{e}}$ are the amount of $\mathrm{E} 2$ removed at time ' $\mathrm{t}$ ' and removal capacity at equilibrium, respectively. $\mathrm{k}_{1}$ and $\mathrm{k}_{2}$ are the pseudo-first and pseudo-second order rate constants, respectively. Similarly, the constants $\mathrm{k}$ and a are referred to the rate constant and fractal constant, respectively. A non-linear least square fitting was conducted and the unknown parameters were optimized. The estimated values of the unknown parameters along with the least square sum were then returned in Table 2. The simulation data was best fitted to the PSO and FL-PSO kinetic models compared to the PFO model since reasonably a low value of least square sum was obtained for these two models. Further, a fair applicability of the PSO or FL-PSO models pointed that the E2 species were bound onto the surface of these hybrid materials with relatively a strong forces. Previously, Patel et al. [11] reported that the adsorption of E2 on bone char obeyed the pseudo second-order kinetic model and they assumed that chemisorption mechanism was involved in the adsorption process. Similar result was obtained in the sorptive removal of bisphenol A by some of the hybrid materials precursor to the natural sericite [22].

\subsubsection{Fixed-bed column reactor operations}

Fixed-bed column reactor studies were performed to assess the loading capacity of the hybrid materials, viz., BCH, BCAH, LCH and LCAH for E2 under the dynamic conditions. The column experiments were conducted with the stated column conditions. The breakthrough curves obtained were presented graphically in Fig. 5. Figure revealed that relatively high breakthrough volume was obtained for E2 by these solids. A complete breakthrough was obtained at the throughput volume of 6.18, 5.40, 4.92 and 4.26; respectively for the BCH, BCAH, LCH and LCAH solids. Relatively high value of breakthrough volume indicated the high removal capacity of E2 by the modified solids under the dynamic conditions as well. This further showed that the modified solids could be potential and promising sorbing materials for the effective attenuation of E2 from aqueous solutions.

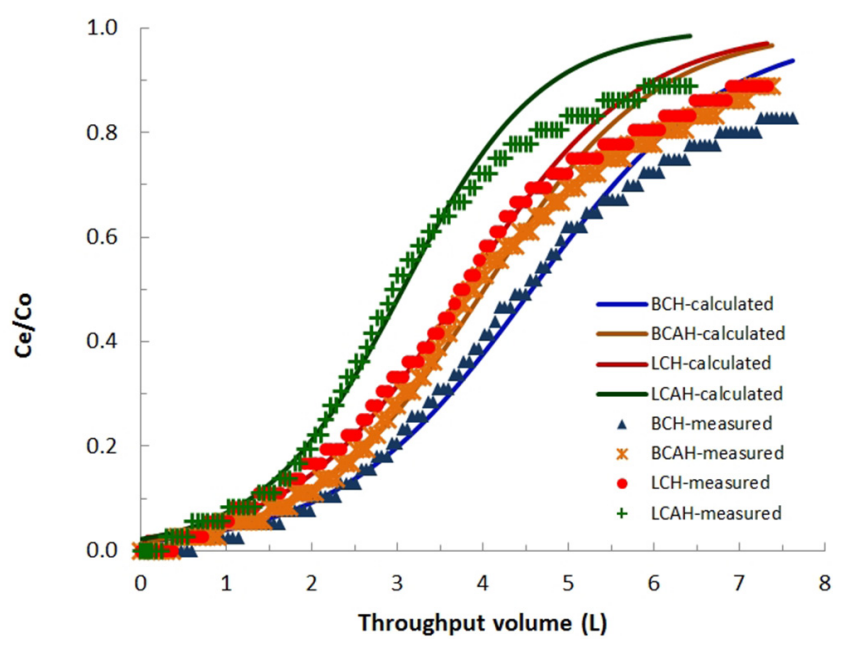

Fig. 5. Breakthrough curves for the removal of E2 using various hybrid

\begin{tabular}{|c|c|c|c|c|c|c|c|c|c|c|}
\hline \multirow{3}{*}{ Systems } & \multicolumn{10}{|c|}{ Kinetic Models } \\
\hline & \multicolumn{3}{|c|}{ PFO } & \multicolumn{3}{|c|}{ PSO } & \multicolumn{4}{|c|}{ FL-PSO } \\
\hline & $\mathbf{q}_{\mathbf{e}}$ & $k_{1}$ & $\mathbf{s}^{2}$ & $\mathbf{q}_{\mathbf{e}}$ & $\mathbf{k}_{2}$ & $\mathbf{s}^{2}$ & $\mathbf{q}_{\mathbf{e}}$ & $\mathbf{k}$ & $\alpha$ & $\mathbf{s}^{2}$ \\
\hline BCH-E2 & 2.264 & 0.952 & 0.195 & 2.378 & 0.656 & 0.049 & 2.726 & 0.480 & 0.464 & 0.003 \\
\hline BCAH-E2 & 2.124 & 0.706 & 0.395 & 2.276 & 0.435 & 0.144 & 3.626 & 0.154 & 0.308 & 0.009 \\
\hline LCH-E2 & 2.208 & 0.841 & 0.304 & 2.340 & 0.546 & 0.098 & 3.040 & 0.298 & 0.368 & 0.009 \\
\hline LCAH-E2 & 1.914 & 0.633 & 0.346 & 2.065 & 0.412 & 0.126 & 3.358 & 0.147 & 0.324 & 0.011 \\
\hline
\end{tabular}
materials.

Table 2. Kinetic Parameters Obtained for the Sorption of E2 by Hybrid Materials Using Various Kinetic Models

$\mathrm{s}^{2}:$ Least Square Sum

Table 3. Thomas Constants (along with the least square sum) Estimated for the Removal of E2 by Various Hybrid Materials

\begin{tabular}{cccc}
\hline \multirow{2}{*}{ Materials } & \multicolumn{2}{c}{ Thomas constants } & Least square sum $\left(\mathbf{s}^{2}\right)$ \\
\cline { 2 - 3 } & $\mathbf{K}_{\mathbf{T}} \times \mathbf{1 0}^{-\mathbf{4}} \mathbf{( \mathbf { L } / \mathbf { m i n } / \mathbf { m g } )}$ & $\mathbf{q}_{\mathbf{o}}(\mathbf{m g} / \mathbf{g})$ & 9.2 \\
$\mathrm{BCH}$ & 1.86 & 75.984 & 10.0 \\
$\mathrm{BCAH}$ & 2.43 & 63.757 & 9.8 \\
$\mathrm{LCH}$ & 2.38 & 58.965 & 16.0 \\
$\mathrm{LCAH}$ & 2.47 & 49.746 & \\
\hline
\end{tabular}


Further, the non-linear least square fitting was conducted with the breakthrough column data using the Thomas equation (Eq. (1)). The fitting was performed to simulate the two unknown parameters, i.e., $\mathrm{K}_{\mathrm{T}}$ and $\mathrm{q}_{\mathrm{o}}$. The values of Thomas constants along with the least square sum were estimated and returned in Table 3. These results indicated that a high loading capacity was achieved for E2 by these solids under the dynamic conditions. Relatively, BCH showed higher removal capacity for E2 compared to the BCAH solid. Similarly, LCH solid possessed relatively higher removal capacity than LCAH solid. The removal capacity followed the trend: $\mathrm{BCH}>\mathrm{BCAH}>\mathrm{LCH}>\mathrm{LCAH}$. These results were similar to the findings of batch reactor experiments. Also, the results were in a line to other reports in which the Thomas equation was utilized to demonstrate the loading capacity of different sorbing materials [18, 31].

\section{Conclusions}

Organo-modified clay and inorgano-organo-modified clay materials, precursor to the natural bentonite and local clay were obtained and efficiently used in the removal of E2 from aqueous solutions. The batch sorption data implied that the high uptake of E2 by the hybrid materials was slightly affected at low and high $\mathrm{pH}$ values. The uptake was insignificantly affected by the change in the sorptive concentration (i.e., from $1.0 \mathrm{mg} / \mathrm{L}$ to $10.0 \mathrm{mg} / \mathrm{L}$ ) and the background electrolyte concentration ( 0.0001 to $0.1 \mathrm{~mol} / \mathrm{L}$ $\mathrm{NaCl}$ ). Moreover, the attenuation of E2 by these hybrid materials was fairly efficient as within 30 min of contact time, an apparent equilibrium between the solid and solution was achieved, and the data was best fitted to the PSO and FL-PSO kinetic models compared to the PFO model. The fixed-bed column results showed that relatively high breakthrough volume were obtained for attenuation of E2 using the hybrid materials, and the loading capacity of E2 was estimated to be 75.984, 63.757, 58.965 and $49.746 \mathrm{mg} / \mathrm{g}$ for the solids $\mathrm{BCH}, \mathrm{BCAH}, \mathrm{LCH}$ and LCAH, respectively. These results, in brief, indicated that the hybrid materials possessed potential application in the remediation of aquatic environment contaminated with the E2.

\section{Acknowledgments}

One of the Author Thanhmingliana wishes to the UGC, New Delhi for financial support as in the form of UGC (NERO) minor project (vide No. F.5-22/2013-14/(MRP/NERO)/261). Also, DT acknowledges the CSIR, New Delhi for partial support as a Major Project (vide No.: 01 (2567)/12/EMR-II).

\section{References}

1. Evgenidou EN, Konstantinou IK, Lambropoulou DA. Occurrence and removal of transformation products of PPCPs and illicit drugs in wastewaters: A review. Sci. Total Environ. 2015;505:905-926.
2. Jiang L, Liu Y, Zeng G, et al. Removal of $17 \beta$-estradiol by few-layered graphene oxide nanosheets from aqueous solutions: External influence and adsorption mechanism. Chem. Eng. J. 2016;284:93-102.

3. Bai X, Casey FXM, Hakk H, DeSutter TM, Oduor PG, Khan E. Sorption and degradation of $17 \beta$-estradiol-17-sulfate in sterilized soil-water systems. Chemosphere 2015;119:1322-1328.

4. Lee JH, Zhou JL, Kim SD. Effects of biodegradation and sorption by humic acid on the estrogenicity of $17 \beta$-estradiol. Chemosphere 2011;85:1383-1389.

5. Hanselman TA, Graetz DA, Wilkie AC. Manure-borne estrogens as potential environmental contaminants: a review. Environ. Sci. Technol. 2003;37:5471-5478.

6. Mashtare ML, Khan B, Lee LS. Evaluating stereoselective sorption by soils of $17 \alpha$-estradiol and $17 \beta$-estradiol. Chemosphere 2011;82:847-852.

7. Hansen PD, Dizer H, Hock B, et al. Vitellogenin- a biomarker for endocrine disruptors. Trac. Trend. Anal. Chem. 1998;17: 448-451.

8. Metcalfe CD, Metcalfe TL, Kiparissis Y, et al. Estrogenic potency of chemicals detected in sewage treatment plant effluents as determined by in vivo assays with Japanese medaka (Oryzias latipes). Environ. Toxicol. Chem. 2001;20:297-308.

9. Zhang Y, Zhou JL. Removal of estrone and 17ß-estradiol from water by adsorption. Wat. Res. 2005;39:3991-4003.

10. Sangster JL, Oke H, Zhang Y, Bartelt-Hunt SL. The effect of particle size on sorption of estrogens, androgens and progestagens in aquatic sediment. J. Hazard. Mater. 2015;299:112-121.

11. Patel S, Han J, Gao W. Sorption of $17 \beta$-estradiol from aqueous solutions on to bone char derived from waste cattle bones: Kinetics and isotherms. J. Environ. Chem. Eng. 2015;3:1562-1569.

12. Yoon Y, Westerhoff P, Snyder SA, Esparza M. HPLC-fluorescence detection and adsorption of bisphenol $\mathrm{A}, 17 \beta$ -estradiol, and $17 \alpha$-ethynyl estradiol on powdered activated carbon. Wat. Res. 2003;37:3530-3537.

13. Zaib Q, Khan IA, Saleh NB, Flora JRV, Park YG, Yoon Y. Removal of bisphenol A and 17ß-estradiol by single-walled carbon nanotubes in aqueous solution: adsorption and molecular modeling. Wat. Air Soil Pollut. 2012;223:281-3293.

14. Sun W, Zhou K. Adsorption of $17 \beta$-estradiol by multi-walled carbon nanotubes in natural waters with or without aquatic colloids. Chem. Eng. J. 2014;258:185-193.

15. McCallum EA, Hyung H, Do TA, Huang CH, Kim JH. Adsorption, desorption, and steady-state removal of $17 \beta$-estradiol by nanofiltration membranes. J. Membr. Sci. 2008;319:38-43.

16. Le Noir M, Lepeuple AS, Guieysse B, Mattiasson B. Selective removal of $17 \beta$-estradiol at trace concentration using a molecularly imprinted polymer. Wat. Res. 2007;41:2825-2831.

17. Lee SM, Tiwari D. Organo and inorgano-organo-modified clays in the remediation of aqueous solutions: An overview. Appl. Clay Sci. 2012;59-60:84-102.

18. Thanhmingliana, Lee SM, Tiwari D, Prasad SK. Efficient attenuation of 17a-ethynylestradiol (EE2) and tetracycline using novel hybrid materials: batch and column reactor studies. RSC AdV. 2015;5:46834-46842.

19. ISRIC, Procedures for soil analysis [Internet]. Reeuwijk: ISRIC; c2002. Available from: http://www.isric.org/isric/webdocs/ 
docs/ISRIC_TechPap09_2002.pdf (2002).

20. EPA, 1986. Method 9080, Cation-exchange capacity of soils (ammonium acetate) [Internet]. Available from: www3.epa. gov/epawaste/hazard/testmethods/sw846/pdfs/9080.pdf.

21. Thanhmingliana, Tiwari D. Efficient use of hybrid materials in the remediation of aquatic environment contaminated with micro-pollutant diclofenac sodium. Chem. Eng. J. 2015;263: 364-373.

22. Thanhmingliana, Lee SM, Tiwari D. Use of hybrid materials in the decontamination of bisphenol A from aqueous solutions. RSC Adv. 2014;4:43921-43930.

23. Thomas HC. Heterogeneous ion exchange in a flowing system. J. Am. Chem. Soc. 1944;66:1664-1666.

24. Park Y, Ayoko GA, Kurdi R, Horváth E, Kristóf J, Frost RL. Adsorption of phenolic compounds by organoclays: Implications for the removal of organic pollutants from aqueous media. J. Colloid Interf. Sci. 2013;406:196-208.

25. Lalhmunsiama, Gupta PL, Pawar RR, Lee SM. Use of algal biomass in the remediation of aqueous waste contaminated with cadmium. Sci. Technol. J. 2015;3:14-20.

26. Joseph L, Zaib Q, Khan IA, et al. Removal of bisphenol A and $17 \alpha$-ethinylestradiol from landfill leachate using single-walled carbon nanotubes. Wat. Res. 2011;45:4056-4068.

27. Lalhmunsiama, Tiwari D, Lee SM. Activated carbon and manganese coated activated carbon precursor to dead biomass in the remediation of arsenic contaminated water. Environ. Eng. Res. 2012;17:S41-S48.

28. Azizian S. Kinetic models of sorption: a theoretical analysis. J. Colloid Interf. Sci. 2004;276:47-52.

29. Ho YS, McKay G. A comparison of chemisorption kinetic models applied to pollutant removal on various sorbents. Proc. Saf. Environ. Protect. 1998;76:332-340.

30. Haerifar M, Azizian S. An exponential kinetic model for adsorption at solid/solution interface. Chem. Eng. J. 2013;215-216: 65-71.

31. Tiwari D, Laldawngliana C, Lee SM. Immobilized small sized manganese dioxide sand in the remediation of arsenic contaminated water. Environ. Eng. Res. 2014;19:107-113. 